\title{
ENSAIOS EXPLORATÓRIOS EM COLUNA DE FLOTAÇÃO DE BANCADA COM MINÉRIO FOSFÁTICO ULTRAFINO
}

\author{
Luciana Pereira Alves ' \\ Luís Alberto Silva' \\ Michelly dos Santos Oliveira ' \\ Fabiano Nunes Capponi ${ }^{2}$
}

\section{Resumo}

Colunas de flotação de bancada estimam a realidade industrial, gerando resultados com elevado grau de consistência e reprodutibilidade. Diante disso, este trabalho teve como objetivo realizar ensaios exploratórios em uma coluna de flotação de bancada, utilizando minério fosfático ultrafino. Testes preliminares, em célula mecânica, foram executados para determinar o tempo de condicionamento e a dosagem dos reagentes. A condição mais adequada foi $500 \mathrm{~g} / \mathrm{t}$ de amido de milho gelatinizado e $250 \mathrm{~g} / \mathrm{t}$ de Flotigam 5806, condicionados por 5 minutos e I minuto, respectivamente. A eficiência da coluna de flotação foi confirmada com base em teores de $\mathrm{P}_{2} \mathrm{O}_{5}$, tomando como referência parâmetros industriais de flotação desse tipo de minério. Analisou-se as variáveis granulometria e vazões de reciclo, de água de lavagem e de ar. O melhor resultado obtido foi vazões de ar, reciclo e água de lavagem de I,2 L/min, 0,95 L/min e 0, I L/min, respectivamente, correspondendo a um teor de $\mathrm{P}_{2} \mathrm{O}_{5}$ de $36,91 \%$ no concentrado e $3,53 \%$ no rejeito, com recuperação metalúrgica de $74,36 \%$.

Palavras-chave: Flotação; Coluna; Fosfato.

\section{EXPLORATORY TESTS BENCH FLOTATION COLUMN WITH ULTRAFINE PHOSPHATIC ORE}

\begin{abstract}
Keywords: Flotation; Column; Phosphate.

\section{INTRODUÇÃO}

Desenvolvido no início do século XIX, o processo de flotação baseia-se nas propriedades físico-químicas de superfície para a separação de diferentes minerais. Aplicado como um método de concentração no tratamento de minérios, este processo avançou tecnologicamente, ao longo do tempo, ganhando grande importância no cenário industrial. A utilização de reagentes específicos permite a
\end{abstract}

Bench columns flotation simulate industrial reality generating results with high reproducibility and consistency. Thus, this study aimed to perform exploratory tests in a bench column flotation using ultrafine phosphatic ore. Preliminary tests were performed in mechanical cells in order to define the conditioning time and reagents dosage. The most appropriate situation was $500 \mathrm{~g} / \mathrm{t}$ of gelatinized corn starch and $250 \mathrm{~g} / \mathrm{t}$ of Flotigam 5806, conditioned for 5 minutes and I minute, respectively. The efficiency of the column flotation was established based on $\mathrm{P}_{2} \mathrm{O}_{5}$ based in industrial flotation parameters for this type of ore. It was analyzed the particle size and flow recycle of wash water and air. The best result was obtained for air, recycle and wash water flow rates of $1.2 \mathrm{~L} / \mathrm{min}, 0.95 \mathrm{~L} / \mathrm{min}$ and $0.1 \mathrm{~L} / \mathrm{min}$, respectively. Representing a content of $36.91 \% \mathrm{P}_{2} \mathrm{O}_{5}$ in the concentrate, and $3.53 \%$ in the waste with metallurgical recovery of $74.36 \%$.

manipulação do grau de hidrofobicidade na superfície das partículas minerais, o que caracteriza a seletividade do processo, Alves [I].

A coluna destaca-se como um equipamento de flotação que apresenta características eficazes na concentração de minérios cada vez mais complexos, de baixos teores e granulometrias de liberação muito finas, Santos [2].

'Departamento de Minas e Construção Civil, Centro Federal de Educação Tecnológica de Minas Gerais - CEFET/MG, Araxá, MG, Brasil.

²Departamento de Concentração, Companhia Brasileira de Metalurgia e Mineração, Araxá, MG, Brasil. 
As colunas apresentam duas zonas distintas: zona de recuperação (ou de coleta), localizada entre o sistema de aeração e a interface polpa-espuma, e zona de limpeza (ou de espuma), localizada entre a interface polpa-espuma e o transbordo. A polpa já condicionada é alimentada a cerca de $2 / 3$ de altura a partir da base do equipamento. $\mathrm{Na}$ zona de recuperação as particulas minerais realizam fluxo contracorrente em relação as bolhas de ar, produzidas por aerador instalado na parte inferior da coluna. As partículas hidrofóbicas são coletadas pelas bolhas que, por fluxo ascendente, transportam-nas à zona de limpeza, formada por uma camada de espuma. As partículas hidrofílicas, por não se aderirem às bolhas, são removidas na base do equipamento. A água de lavagem, adicionada na parte superior da coluna, sob condiçóes adequadas, realiza a limpeza da espuma pela eliminação de partículas contaminantes, Aquino et al. [3].

A partícula mineral na coluna de flotação é coletada pelas bolhas de ar por meio de um dos seguintes processos: I) colisão partícula-bolha seguido de adesão devido a natureza hidrofóbica da superfície do mineral; ou 2) arraste hidrodinâmico da partícula. A característica principal da coluna de flotação é que a recuperação de partículas transportadas por arraste pode ser praticamente eliminada, Finch e Dobby [4].

As melhorias substanciais na qualidade dos concentrados obtidos nas colunas em diversas unidades industriais, operando com diferentes tipos de minérios, somados aos ganhos no desempenho metalúrgico e à economia nos custos de capital e de operação, demonstram a importância desse equipamento para a indústria mineral. Tais fatores tem sido decisivos para a aplicação das colunas em processos de flotação, tanto para novos projetos, como para expansões industriais, Caldara e Correia [5].

Segundo Gu e Yalcin [6], o estudo e a otimização das variáveis que influenciam o desempenho metalúrgico da coluna, tais como a espessura da camada de espuma, a vazão de ar, a densidade da polpa, a adição de água de lavagem, assim como as variáveis relativas aos reagentes, devem ser realizados em colunas. Os testes apresentados pelos autores com uma coluna de flotação semi-batelada demonstraram um elevado grau de consistência e reprodutibilidade. Embora células de flotação mecânica de bancada estejam disponíveis para o estudo de flotação, opções com a coluna são limitadas.

Considerando os aspectos mencionados, foi implantada uma coluna de flotação de bancada no CEFET/MG, Unidade Araxá. $O$ presente trabalho objetivou a realização de ensaios exploratórios de flotação na coluna, com minério fosfático ultrafino. Foram analisadas as variáveis: tempo de condicionamento, dosagem de reagentes, granulometria, vazão de reciclo, de água de lavagem e de ar. A eficiência do processo foi quantificada com base em teores e recuperações obtidos nos testes.

Industrialmente, o objetivo da flotação de apatita é a obtenção de teores de aproximadamente $33,00 \%$ de $\mathrm{P}_{2} \mathrm{O}_{5}$ no concentrado e $4,00 \%$ no rejeito, segundo Santos [7].

\section{METODOLOGIA}

\section{I Amostra}

A amostra de minério fosfático utilizada neste estudo foi coletada na alimentação do circuito de flotação de minérios ultrafinos no Complexo de Mineração de Tapira/MG (CMT), pertencente à empresa Vale Fertilizantes. A distribuição granulométrica da amostra global foi determinada por difração de raios laser utilizando Cilas 1090. O teor das espécies químicas presentes foi determinado por Espectrômetro de Fluorescência de Raios X, no Laboratório de Análises da referida empresa.

\subsection{Unidade Experimental}

A coluna de flotação foi construída em acrílico e possui $2,5 \mathrm{~m}$ de altura com diâmetro interno de $42 \mathrm{~mm}$. A seção de aeração possui diâmetro de $165 \mathrm{~mm}$ e $150 \mathrm{~mm}$ de altura. Um esquema detalhado da unidade experimental e a coluna de flotação implantada são apresentados nas Figura IA, B, respectivamente.

Um gotejador acoplado a uma mangueira de abastecimento de água, instalado no topo da coluna, promove a lavagem da espuma, sem provocar turbulência. A vazão de água é controlada por um rotâmetro com faixa de 0,1 a 2,0 L/min. As bolhas são geradas por um tubo poroso na base da coluna. Uma linha de ar comprimido supre $o$ ar utilizado nos ensaios e tem vazão controlada por rotâmetro ( 0 a 4,0 L/min).

A polpa é depositada em uma caixa plástica ligada a uma tubulação que direciona o material a uma bomba peristáltica para alimentar a coluna. Ao final da alimentação, a mesma bomba capta na base do equipamento a polpa afundada e realiza o reciclo. Ao final do ensaio, quando a interface polpa-espuma atinge o topo da coluna, o afundado é coletado na base através da abertura de uma válvula, de forma manual. A Figura 2 apresenta um exemplo de interface polpa-espuma.

\subsection{Condicionamento da Polpa}

Para definição da dosagem de reagentes e tempo de condicionamento, foram realizados ensaios em célula mecânica Denver. Como coletor foi utilizado ácido graxo Flotigam 5806, fornecido pela Clariant, saponificado com proporção óleo:soda de 7:I, obtendo uma solução de 2,5\%. Como depressor foi utilizado amido de milho gelatinizado com proporção amido:soda de 4: I, formando uma solução de $3 \%$. Solução de $\mathrm{NaOH}$ a $10 \%$ foi empregada como regulador de $\mathrm{pH}$. A polpa foi condicionada com $50 \%$ de sólidos e flotada com $25 \%$. A preparação das soluções de coletor e depressor foi baseada no procedimento adotado no estudo de Oliveira et al. [8].

As dosagens de reagentes empregadas neste trabalho foram determinadas a partir de parâmetros industriais para 


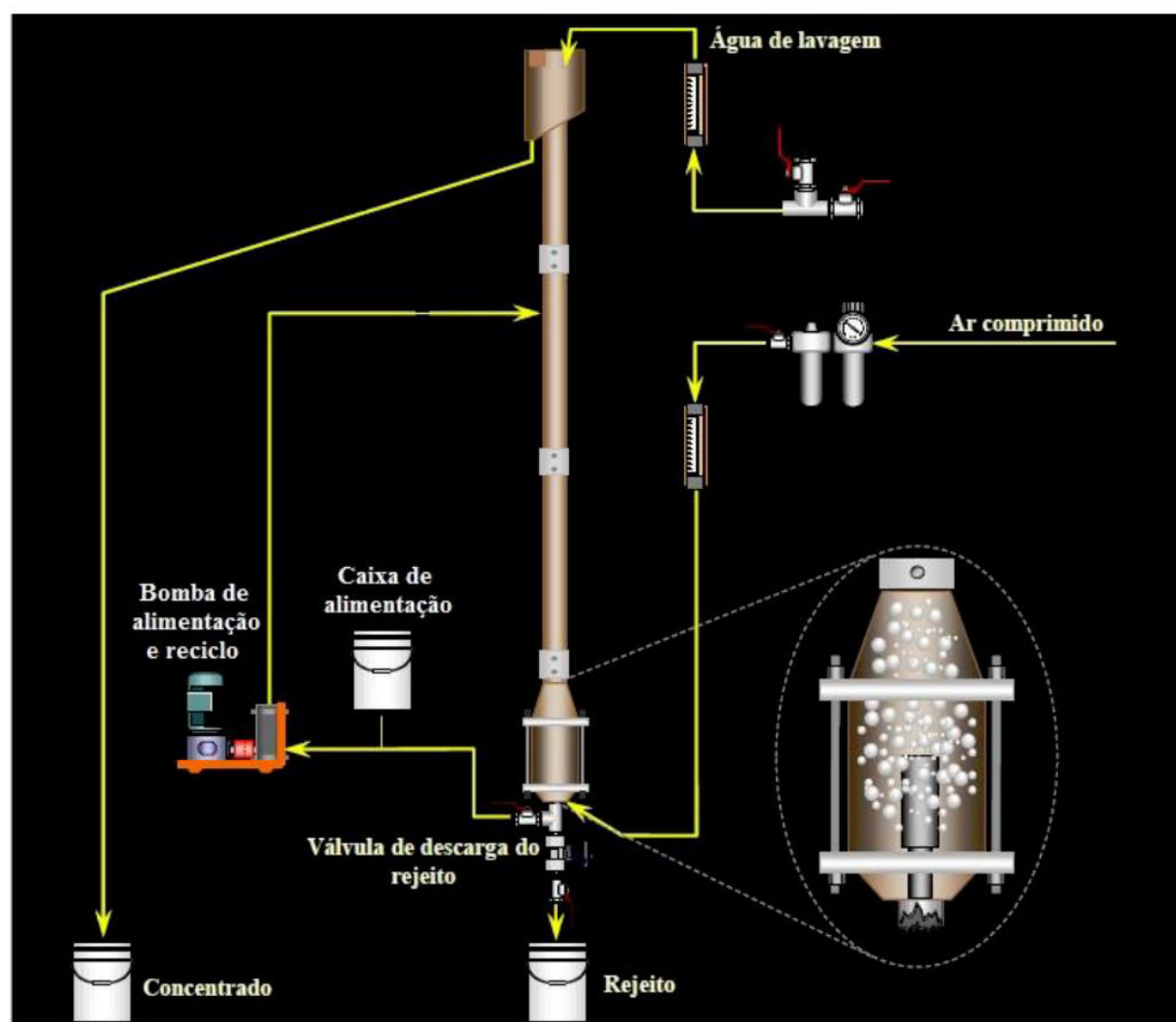

(A)

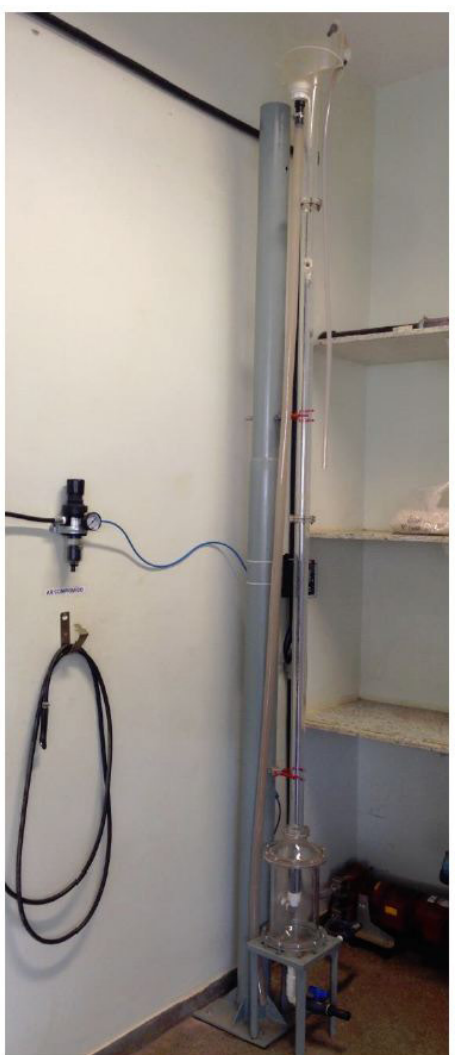

(B)

Figura I. (A) Esquema detalhado da Unidade Experimental; (B) Coluna de Flotação implantada.

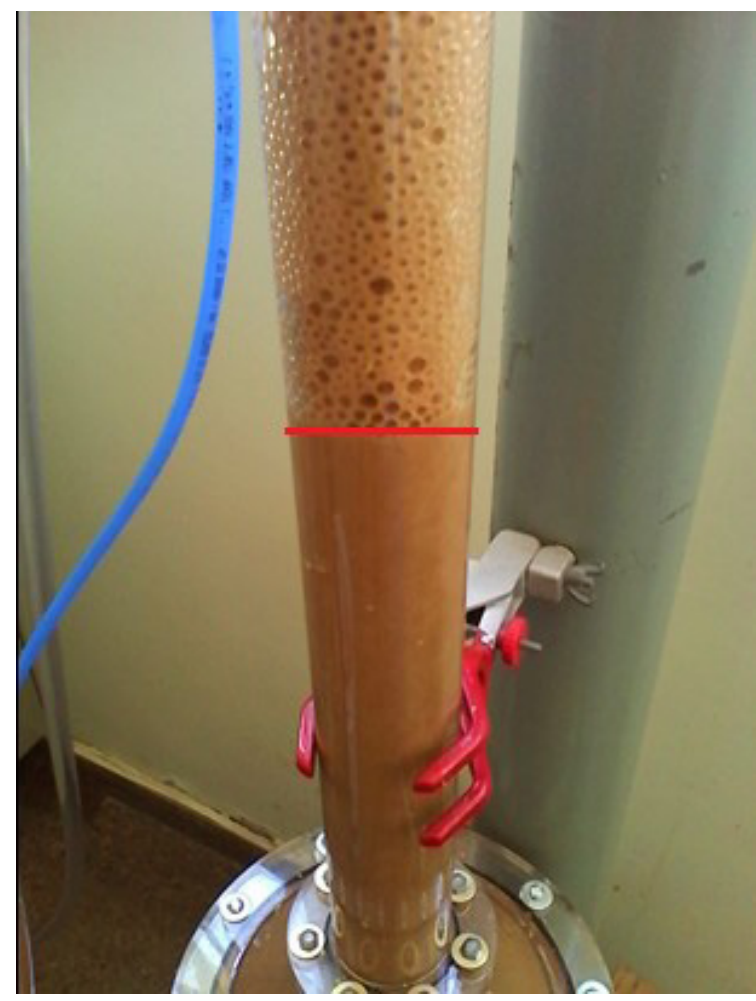

Figura 2. Interface polpa-espuma. flotação deste tipo de minério. Na primeira etapa, a dosagem de coletor foi variada em $150 \mathrm{~g} / \mathrm{t}, 200 \mathrm{~g} / \mathrm{t}, 250 \mathrm{~g} / \mathrm{t}$ e $300 \mathrm{~g} / \mathrm{t}$. Manteve-se constante a dosagem de depressor em $500 \mathrm{~g} / \mathrm{t}$ e os tempos de condicionamento de depressor em 5 minutos e de coletor em I minuto. Na segunda etapa, o tempo de condicionamento de depressor foi variado em 3, 5 e 7 minutos e de coletor em I, 3 e 5 minutos, mantendo-se constante a dosagem de reagentes, sendo $500 \mathrm{~g} / \mathrm{t}$ e $250 \mathrm{~g} / \mathrm{t}$ de depressor e coletor, respectivamente. A dosagem de reagentes e o tempo de condicionamento considerados mais adequados foram empregados nos ensaios de flotação em coluna.

\subsection{Planejamento Experimental}

O processo de flotação em coluna conta com diversas variáveis, assim a análise e planejamento dos experimentos é mais confiável utilizando técnicas estatísticas para esse fim, Oliveira et al. [8]. O método do planejamento fatorial de experimentos foi empregado no planejamento dos ensaios.

Inicialmente as variáveis vazão de ar, de água de lavagem e de reciclo foram analisadas de forma a se realizar uma varredura. Os valores de vazão de ar adotados foram determinados respeitando os intervalos de velocidade

Tecnol. Metal. Mater. Miner., São Paulo, 
superficial do ar empregados em condições típicas de operação, que, segundo Santana et al. [9], situa-se entre I, 0 e $3,0 \mathrm{~cm} / \mathrm{s}$.

Os ensaios preliminares demonstraram a necessidade de adequação nos níveis de vazão de ar e de água de lavagem. Os níveis de vazão de reciclo foram mantidos, assim como a vazão mínima de ar. Para a vazão de água de lavagem, observou-se a necessidade de utilização de um valor inferior a 0,2 L/min. Na Tabela I, estão apresentadas as variáveis e os níveis estudados de acordo com o planejamento de experimentos.

Nos testes para avaliação do efeito da granulometria, duas faixas foram empregadas: uma global de $-80 \#+325 \#$ $(-0,177 \mathrm{~mm}+0,044 \mathrm{~mm})$, correspondente à faixa granulométrica da amostra coletada no circuito industrial, e outra de $-200 \#+325 \#(-0,074 m m+0,044 m m)$, preparada no laboratório. Nestes testes foram aplicadas vazões de ar de I,2 L/min, 0,48 L/min de reciclo e $0,1 \mathrm{~L} / \mathrm{min}$ de água de lavagem. Em todos os ensaios com a coluna, a polpa foi condicionada com $60 \%$ de sólidos, mantendo o $\mathrm{pH}$ em 9,5 , e flotada com $15 \%$ de sólidos.

Tabela I. Variáveis do planejamento executado

\begin{tabular}{|c|c|c|c|c|}
\hline Ensaio & $\begin{array}{c}\text { Vazão de } \\
\text { Ar (L/min) } \\
\text { XI }\end{array}$ & $\begin{array}{c}\text { Vazão de } \\
\text { Reciclo (L/min) } \\
\text { X2 }\end{array}$ & XI & $\times 2$ \\
\hline I & $\mathrm{I}, 2$ & 0,48 & -1 & -1 \\
\hline 2 & 2,0 & 0,48 & +1 & -1 \\
\hline 3 & 2,0 & 0,95 & +1 & +1 \\
\hline 4 & $\mathrm{I}, 2$ & 0,95 & -1 & +1 \\
\hline
\end{tabular}

\section{RESULTADOS E DISCUSSÃO}

\section{I Caracterização da Amostra}

A composição química da amostra de alimentação está apresentada na Tabela 2. Os parâmetros $\mathrm{d}_{50}$ e $\mathrm{d}_{80}$, obtidos na análise granulométrica, foram 0,053 mm e 0,109 mm, respectivamente.

\subsection{Dosagem de Reagente e Tempo de Condicionamento}

A Figura 3 apresenta os resultados dos testes realizados variando a dosagem de coletor. Pode-se observar na Figura 3A, que a recuperação metalúrgica aumentou com 0 aumento da dosagem de coletor. Isso se deve ao fato de que dosagens de coletor maiores tendem a hidrofobizar mais partículas minerais, com isso, obtém-se maior recuperação. Analisando a Figura $3 \mathrm{~B}$, observa-se que a dosagem de $150 \mathrm{~g} / \mathrm{t}$ resultou no maior teor de $\mathrm{P}_{2} \mathrm{O}_{5}$, porém com a menor recuperação metalúrgica e o maior teor de $\mathrm{P}_{2} \mathrm{O}_{5}$ no rejeito, acima de $4 \%$. Foi definida como ótima a dosagem de $250 \mathrm{~g} / \mathrm{t}$, por apresentar uma recuperação metalúrgica expressiva $(7 / \%)$ com teor de $\mathrm{P}_{2} \mathrm{O}_{5}$ no rejeito dentro da especificação. Sendo assim, essa dosagem foi adotada para a realização dos próximos ensaios variando o tempo de contato do mineral com os reagentes, os resultados estão apresentados na Figura 4.

A maior recuperação metalúrgica, de acordo com a Figura 4A, condicionando a polpa com o depressor por 3 minutos, foi obtida para o tempo de condicionamento do coletor igual a 3 minutos. Condicionando com o amido de milho por 5 minutos, a recuperação metalúrgica não variou significativamente. Considerando o tempo de

Tabela 2. Análise química da amostra utilizada neste estudo

\begin{tabular}{lccccccccccc}
\hline \multicolumn{10}{c}{ Amostra: Minério fosfático ultrafino } \\
\hline Espécie & $\mathrm{P}_{2} \mathrm{O}_{5}$ & $\mathrm{Fe}_{2} \mathrm{O}_{3}$ & $\mathrm{MgO}$ & $\mathrm{CaO}$ & $\mathrm{Al}_{2} \mathrm{O}_{3}$ & $\mathrm{Nb}_{2} \mathrm{O}_{5}$ & $\mathrm{SiO}_{2}$ & $\mathrm{TiO}_{2}$ & $\mathrm{BaO}$ & $\mathrm{SrO}$ & $\mathrm{MnO}$ \\
Teor $(\%)$ & 10,78 & $20,2 \mathrm{I}$ & 5,25 & 17,44 & 4,42 & 0,16 & 20,49 & 7,57 & 0,58 & $0,4 \mathrm{I}$ & 0,3 \\
\hline
\end{tabular}

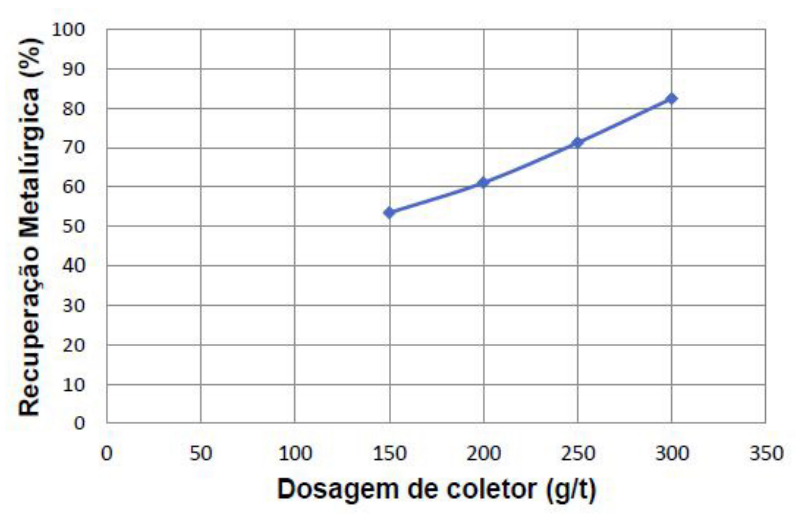

(A)

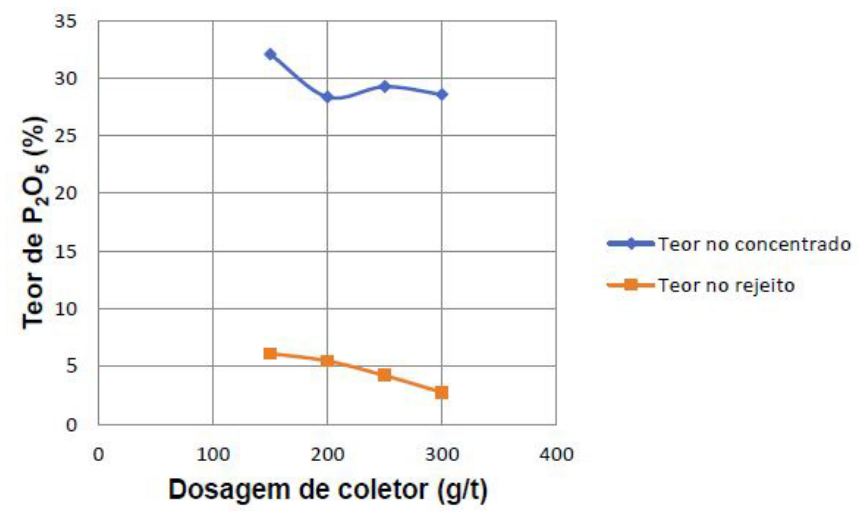

(B)

Figura 3. (A) Recuperação metalúrgica em função da dosagem de coletor; (B) Teor de $P_{2} O_{5}$ no concentrado e rejeito em função da dosagem de coletor. 
condicionamento do depressor igual a 7 minutos, a maior recuperação metalúrgica foi para o tempo de condicionamento do coletor igual a 5 minutos. A Figura $4 \mathrm{~B}$ mostra a diminuição do teor de $\mathrm{P}_{2} \mathrm{O}_{5}$ no concentrado com aumento do tempo de condicionamento do ácido graxo, para 3 e 5 min de condicionamento de depressor. No entanto, a Figura 4B mostra que com 7 minutos de condicionamento do amido e I minuto de coletor obteve-se o menor teor de $\mathrm{P}_{2} \mathrm{O}_{5}$ no concentrado, dentre todos os ensaios, em torno de $23 \%$. A justificativa está no fato de que provavelmente o amido de milho deprimiu a apatita, diminuindo assim a seletividade do processo.

Os tempos de condicionamento de I minuto para o coletor e de 5 minutos para o depressor foram escolhidos como melhores condições para realizar os demais ensaios. Embora o tempo ótimo de condicionamento do ácido graxo, levando em consideração apenas a recuperação metalúrgica, mostrado na Figuras $4 \mathrm{~A}$, ser de 5 minutos, quando avalia-se a Figura 4B, observa-se que o teor de $\mathrm{P}_{2} \mathrm{O}_{5}$ no concentrado diminuiu, em torno de $5 \%$, com o aumento do tempo de contato do coletor com o mineral de I para 3 minutos, ficando muito abaixo do especificado, $33 \%$ de $\mathrm{P}_{2} \mathrm{O}_{5}$ no concentrado.

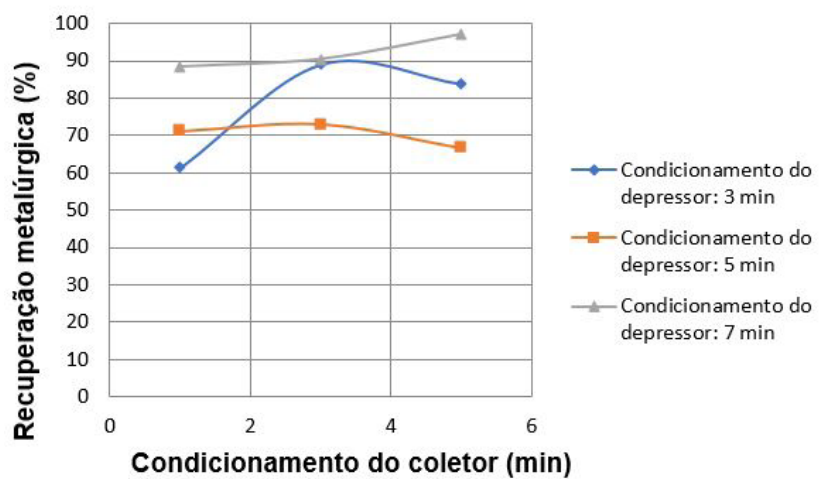

(A)
Isto se deve ao fato da cinética de adsorção do ácido graxo Flotigam 5806 na superfície da apatita, desse depósito, ser rápida, sendo então I minuto um tempo suficiente para a coleta do mineral apatita. Além disso, com 5 minutos de condicionamento do amido e I minuto de condicionamento do óleo vegetal obteve-se menor teor de $\mathrm{P}_{2} \mathrm{O}_{5}$ no rejeito, em relação ao que se observa no condicionamento com coletor por 3 minutos, além de um teor de $\mathrm{P}_{2} \mathrm{O}_{5}$ no concentrado satisfatório (em torno de $29 \%$ ).

\subsection{Ensaios na Coluna de Flotação}

Nos ensaios preliminares, observou-se grande turbulência atribuída às vazões de água de lavagem consideradas inicialmente. Por esta razão, optou-se pela modificação dos valores adotados. Foi possível observar que a vazão de 0, I L/min (velocidade superficial de $0,12 \mathrm{~cm} / \mathrm{s}$ ) apresentou um resultado mais satisfatório, sendo então utilizada no planejamento executado, apresentado na Tabela I.

Foi adotado como nível máximo para variável vazão de ar 2,0 L/min (velocidade superficial de 2,4 cm/s) e mínimo igual a I,2 L/min (velocidade superficial de I, $4 \mathrm{~cm} / \mathrm{s}$ ). A Figura 5

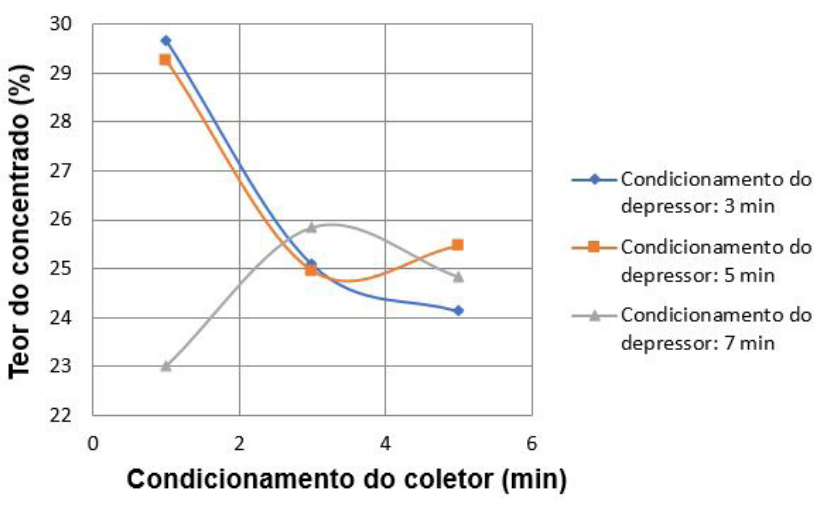

(B)

Figura 4. (A) Recuperação metalúrgica; (B) Teor do concentrado em função do tempo de condicionamento do coletor.

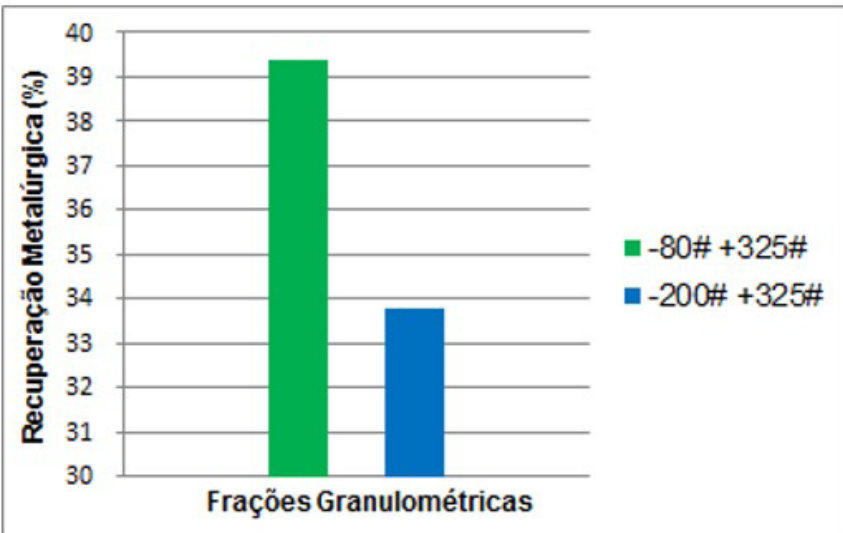

(A)

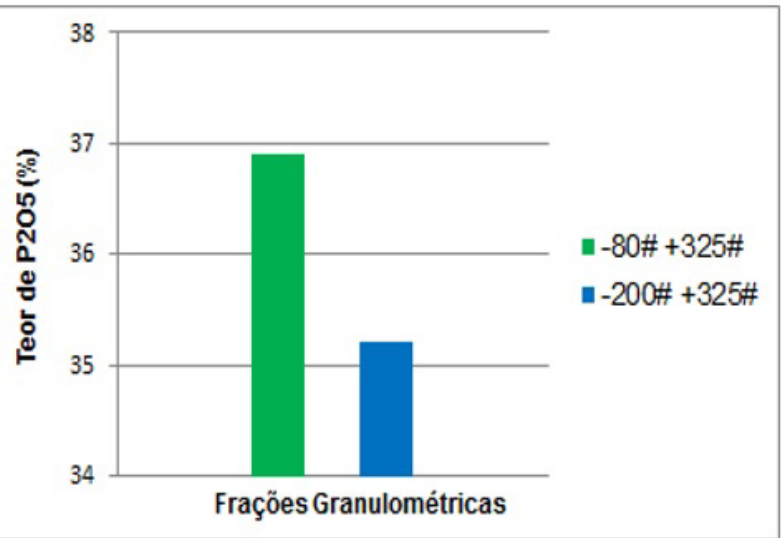

(B)

Figura 5. Zona de recuperação para: (A) vazão de ar de I,2 L/min; (B) vazão de ar de 2,0 L/min.

Tecnol. Metal. Mater. Miner., São Paulo, 
apresenta o efeito, na zona de recuperação, observado para estas vazões apenas com água e ar. Observa-se que, nas condições executadas utilizando vazão de ar de I,2 L/min formaram-se bolhas aparentemente estáveis, com mínima coalescência e turbulência. $O$ aumento da vazão de ar para 2,0 L/min gera maior quantidade de bolhas, o que pode ser observado comparando-se as respectivas Figura 5A, B. Espera-se que a recuperação de partículas minerais cresça com o aumento da vazão de ar, contudo, o valor máximo considerado não deve ser excessivo a ponto de gerar a presença de coalescência e turbulência na zona de recuperação, o que pode alterar significativamente a eficiência do processo.

A Figura 6 apresenta os resultados da flotação em coluna para duas faixas granulométricas. Pela Figura 6A, pode-se afirmar que $\circ$ teste com faixa granulométrica global (cuja fração corresponde a $-80 \#+325 \#$ ), resultou em maior recuperação metalúrgica. Isto pode ser explicado pelo fato das partículas finas apresentarem maior área superficial com maior disponibilidade de sítios ativos para adsorção do coletor em relação às partículas grossas, e por isso, apresentam maior consumo de reagente. Como a quantidade de coletor utilizada foi a mesma, a recuperação da fração fina foi menor.

Como pode ser observado na Figura 6B, a fração granulométrica $-200 \#+325$ \# apresentou menor teor de $\mathrm{P}_{2} \mathrm{O}_{5}$ em relação à fração $-80 \#+325 \#$. Isso pode ser justificado em razão do fenômeno denominado de entrainment, que corresponde ao arraste de partículas hidrofilicas para a espuma a partir da existência de uma quantidade de água entre as bolhas de ar ou nos interstícios dos agregados de partículas com as bolhas, Santana et al. $[9,10]$. Além disso, a maior energia livre superficial dos finos pode provocar a adsorção não seletiva de reagentes, e espécies dissolvidas na água, de forma a dificultar a seletividade do processo, de acordo com Baltar [ II].

Os teores de $\mathrm{P}_{2} \mathrm{O}_{5}$ são apresentados na Tabela 3, juntamente com as recuperações metalúrgica e mássica para os testes do planejamento experimental, descrito na Tabela I. Observa-se na Tabela 3 que o maior teor de $\mathrm{P}_{2} \mathrm{O}_{5}$ foi obtido no ensaio 2 , onde a coluna foi operada com vazão de ar (XI) de 2,0 L/min e vazão de reciclo $(X 2)$ de $0,48 \mathrm{~L} / \mathrm{min}$. O menor foi obtido no ensaio I, cuja vazão de ar foi de I, $2 \mathrm{~L} / \mathrm{min}$ e $0,48 \mathrm{~L} / \mathrm{min}$ de reciclo. Nos ensaios 3 e 4, onde empregou-se reciclo de $0,95 \mathrm{~L} / \mathrm{min}$ foram observadas maiores recuperações e teores muito próximos. A vazão de reciclo maior resulta em maior probabilidade de colisão bolha-partícula, portanto em maior recuperação.

De acordo com o trabalho de Santos [7], desenvolvido no mesmo complexo industrial (CMT), o objetivo da flotação de apatita é a obtenção de teores de aproximadamente $33,00 \%$ de $\mathrm{P}_{2} \mathrm{O}_{5}$ no concentrado e $4,00 \%$ no rejeito. Este fator demonstra a potencialidade do equipamento instalado, uma vez que foi possível, com apenas uma etapa

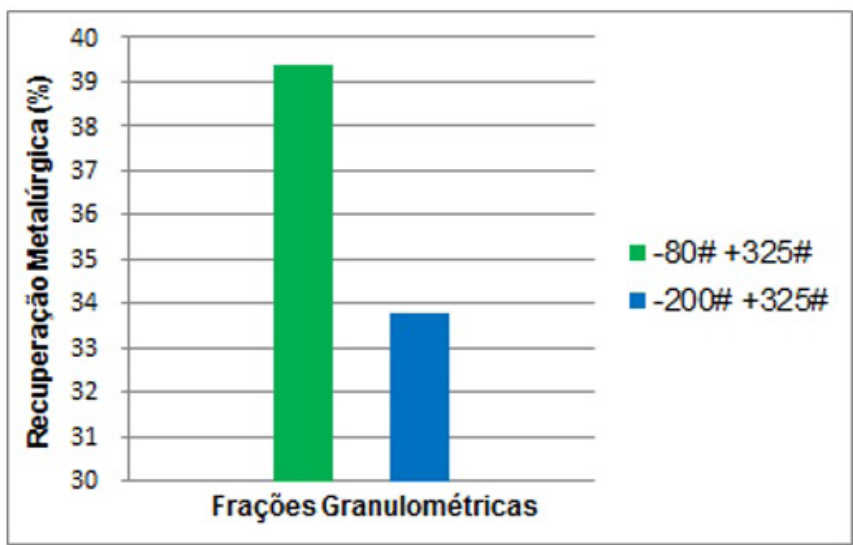

(A)

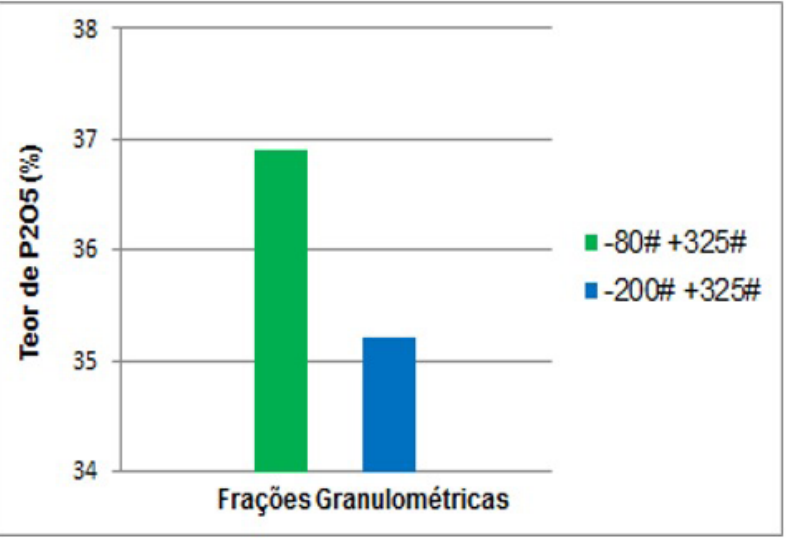

(B)

Figura 6. (A) Recuperação metalúrgica em função das diferentes faixas granulométricas; (B) Teor do concentrado em função das diferentes faixas granulométricas.

Tabela 3. Teores e Recuperações Metalúrgica e Mássica por ensaio

\begin{tabular}{ccccccc}
\hline Ensaio & XI* & X2** & $\begin{array}{c}\text { Teor } \mathbf{P}_{\mathbf{2}} \mathbf{O}_{\mathbf{5}} \\
\text { Concentrado (\%) }\end{array}$ & $\begin{array}{c}\text { Teor } \mathbf{P}_{\mathbf{2}} \mathbf{O}_{\mathbf{5}} \\
\text { Rejeito (\%) }\end{array}$ & $\begin{array}{c}\text { Recuperação } \\
\text { Metalúrgica (\%) }\end{array}$ & $\begin{array}{c}\text { Recuperação } \\
\text { Mássica (\%) }\end{array}$ \\
\hline $\mathbf{I}$ & 1,2 & 0,48 & 34,77 & 6,80 & 45,89 & 14,23 \\
$\mathbf{2}$ & 2,0 & 0,48 & 37,62 & 4,68 & 64,62 & 18,52 \\
$\mathbf{3}$ & 2,0 & 0,95 & 36,77 & 4,16 & 69,24 & 20,30 \\
$\mathbf{4}$ & 1,2 & 0,95 & 36,91 & 3,53 & 74,36 & 21,72 \\
\hline
\end{tabular}

*Vazão de ar (L/min); **Vazão de reciclo (L/min). 
de flotação em coluna, a obtenção de produtos que atendem às especificações adotadas industrialmente.

Em referência a esta afirmativa, pode-se citar um estudo realizado em coluna de flotação de bancada, relativo ao processo de concentração de minério fosfático oriundo do Complexo Carbonatítico do Barreiro, localizado em Araxá, MG. Dentre as conclusões, Guimarães e Peres [12] atestam que foi observada a mesma seletividade e recuperação, com níveis levemente menores ( $2 \%$ e $3 \%$, respectivamente), em comparação com resultados industriais, para a mesma dosagem de reagentes, empregando-se metodologia desenvolvida para a flotação de barita e apatita em uma coluna de batelada. Os autores destacaram que, o controle do processo de flotação monitorado em escala laboratorial com células mecânicas de bancada foi inadequado devido a discrepância com a prática industrial.

\section{CONCLUSÃO}

Colunas de flotação de bancada apresentam-se como uma eficaz alternativa para estudos como demonstrado em diversos trabalhos (Fortes et al. [13]; Fortes et al. [14]; Batistella [15]; Testa e Rubio [16]; Santos et al. [17]) realizados nesse tipo de equipamento. Os ensaios reproduzem com maior eficiência a realidade industrial cuja concentração mineral se dá por flotação em coluna, o que é observado como tendência, reportando a resultados mais satisfatórios e representativos.

Os teores de $\mathrm{P}_{2} \mathrm{O}_{5}$ nos concentrados e nos rejeitos obtidos nesse estudo se aproximam significativamente da especificação industrial, demonstrando a potencialidade da coluna de flotação de bancada instalada.

A condição operacional para coluna de flotação que forneceu os resultados mais satisfatórios, considerando os fatores analisados, foi: vazão de ar de I,2 L/min, reciclo de $0,95 \mathrm{~L} / \mathrm{min}$ e água de lavagem de $0, \mathrm{I} \mathrm{L} / \mathrm{min}$. Para este ensaio foram obtidos teor de $36,91 \%$ de $\mathrm{P}_{2} \mathrm{O}_{5}$ no concentrado, $3,53 \%$ no rejeito e $74,36 \%$ de recuperação metalúrgica.

Com relação à granulometria, o melhor resultado foi obtido no ensaio com fração granulométrica de $-80 \#+325 \#$ que corresponde à alimentação da coluna de ultrafinos industrial, onde a amostra em estudo foi coletada.

\section{Agradecimentos}

Os autores agradecem ao apoio financeiro, imprescindível para o desenvolvimento do presente trabalho, da agência FAPEMIG (20I4, TEC - APQ-0IIIII-I3), à Companhia Brasileira de Metalurgia e Mineração, pela doação de parte da unidade experimental, à Vale Fertilizantes, unidade Tapira - MG, pelo fornecimento da amostra.

\section{REFERÊNCIAS}

I Alves LP. Implantação de coluna de flotação no Laboratório de Tratamento de Minérios do CEFET/MG, Unidade Araxá e realização de estudo exploratório [monografia]. Araxá: Centro Federal de Educação Tecnológica de Minas Gerais; 2015.

2 Santos EP. Alternativas para o tratamento de ultrafinos de minério de ferro da Mina do Pico/MG por flotação em coluna [dissertação de mestrado]. Porto Alegre: Universidade Federal do Rio Grande do Sul; 2010.

3 Aquino JA, Oliveira MLM, Fernandes MD. Flotação em coluna. In: Luz AB, Sampaio JA, Almeida SLM. Tratamento de minérios. 4. ed. Rio de Janeiro: CETEM/MCT; 20I 0. p. 459-494.

4 Finch JA, Dobby GS. Column flotation. Toronto: Pergamon Press; 1990.

5 Caldara JA, Correia JCG. Abordagem sobre a aplicação da flotação em coluna em beneficiamento mineral. Rio de Janeiro: CETEM/MCT; 20I0. 18 p.

6 Gu LP, Yalcin T. Semi-batch flotation column. Minerals Engineering. 2012;26:105-107.

7 Santos LH. Avaliação dos efeitos da dosagem de depressor e do pH da polpa na flotação de minério fosfático: um estudo experimental de caso [monografia]. Belo Horizonte: Universidade Federal de Minas Gerais; 2012.

8 Oliveira MS, Santana RC, Ataíde CH, Barrozo MAS. Recovery of apatite from flotation tailings. Separation and Purification Technology. 201 1;79:79-84.

9 Santana RC, Duarte CR, Ataíde CH, Barrozo MAS. Flotation selectivity of phosphate ore: effects of particle size and reagent. Separation Science and Technology. 201 I;46:15II-I5I8.

10 Santana RC, Santos MA, Santos TCM, Souza TAA, Ataíde CH, Barrozo MAS. Granulometric characterization of flotation products. Materials Science Forum. 2012;727-728: 1902-1907.

I I Baltar CAM. Flotação no tratamento de minérios. 2. ed. Recife: Editora UFPE; 2010.

12 Guimarães RC, Peres AEC. Interfering ions in the flotation of a phosphate ore in a batch column. Minerals Engineering. 1999; 12:757-768. 
Alves et al.

13 Fortes MCB, Silva AAM, Guimarães RC, Ataíde CH, Barrozo MAS. Pre-separation of Siliceous gangue in apatite flotation. Industrial \& Engineering Chemistry Research. 2007;46:7027-7029.

14 Fortes MCB, Silva AAM, Ceolin SP, Ataíde CH, Guimarães RC, Barrozo MAS. Selective siliceous ore flotation for futher apatite recovery. Materials Science Forum. 2006;531:728-733.

15 Batistella MA. Flotação em coluna sem adição de água de limpeza: fundamentos e aplicações [dissertação de mestrado]. Porto Alegre: Universidade Federal do Rio Grande do Sul; 2009.

16 Testa FG, Rubio J. O condicionamento em alta intensidade como alternativa real para o aumento da recuperação de partículas finas. Brasil Mineral (São Paulo). 2008;278:96-103.

17 Santos MA, Santana RC, Capponi F, Ataíde CH, Barrozo MAS. Influence of the water composition on the selectivity of apatite flotation. Separation Science and Technology. 2012;47:606-6I2.

Recebido em: 8 Jan. 2016

Aceito em: 12 Jul. 2016 